\title{
NATURA I DESTRUCCIÓ: \\ ELS PLECS POĖTICS DE LA GUERRA \\ DELS SEGADORS (1640-1652)
}

\author{
NATURE AND DESTRUCTION: \\ THE POETIC PAMPHLETS OF THE WAR \\ OF THE REAPERS (1640-1652)
}

Conxita DOMÈnech

University of Wyoming

\section{RESUMEN}

La Guerra dels Segadors (1640-1652) va produir un boom de la paraula escrita sense precedents. Espases, mosquets i trabucs ja no són les úniques armes utilitzades; ara, sermons, cançons i poemes lluitaran en aquesta guerra moderna i propagandística. Els plecs poètics de la guerra segueixen un mateix format i estructura i, sobretot, incorporen una simbologia apta per encendre els ànims de tots els catalans. Catalunya esdevé una família unida: mares, pares, fills i germans s'agrupen contra les forces castellanes. Aquesta família catalana viu al camp o a una arcàdia de rius cabalosos, de valls verdes i d'horts exuberants que els castellans intentaran destruir.

Palabras clave: Felip IV, Guerra dels Segadors, plecs poètics, propaganda

\begin{abstract}
The War of the Reapers (1640-1652) produced a boom of the written word without precedents. Swords, muskets, and blunderbuss were not the only weapons used; sermons, songs, and poems would be utilized to fight this modern and propagandistic war. The poetic pamphlets from the war follow the same format and structure and, above all, they incorporate suitable symbolism that ignites motivation in all Catalans and metaphorically constructs Catalonia as a united family, where mothers, fathers, sons, daughters, brothers, and sisters battle Castilian forces. This unified Catalan family resides in the countryside or in an arcadia of mighty rivers, green valleys, and luscious gardens that the Castilians would attempt to destroy.
\end{abstract}

Keywords: Philip IV, War of the Reapers, poetic pamphlets, propaganda 


\section{INTRODUCCIÓ}

Amb l'entrada de Juan José d'Àustria (1629-1679) a Barcelona l'1 1 d'octubre de 1652, la Guerra de Catalunya finalitza. La població catalana s'oblida momentàniament de la mort i de la desolació, i celebra amb entusiasme el nomenament del nou virrei de Catalunya. El fill del rei promet el perdó dels catalans i, alhora, proclama una nova prohibició d'imprimir qualsevol escrit que no passi per una censura rigorosa. ${ }^{1}$ Les impremtes barcelonines de Jaume Romeu, de Jaume Matevat i de Gabriel Nogués havien tancat les seves portes feia anys, i ja no quedava cap vestigi de propaganda escrita en català. Els fullets catalans s'han prohibit i s'han instaurat unes noves lleis en les quals es reflecteix el poder de la paraula escrita. Els grans perdedors de la Guerra dels Segadors van ser els papers catalans. Les relacions, els sermons, els discursos, els pregons, els avisos, les cartes, les cançons $\mathrm{i}$ els poemes en català, escrits durant la guerra, sucumbiran amb I'entrada de les tropes felipistes a Barcelona. La vida d'aquests fullets va ser curta però fructífera, amb una activitat intensa durant els dos primers anys de la guerra. ${ }^{2}$

Henry Ettinghausen inicia un dels seus molts treballs sobre els pamflets de la guerra amb l'epígraf "War sells papers". La guerra, sens dubte, canvia les lectures i, també, altera la manera de llegir. Els catalans volen estar assabentats i volen una informació ràpida i fiable. La crisi del llibre, la manca del paper i de la tinta, les dificultats econòmiques, la rapidesa en la qual

1 En realitat, la prohibició i la censura estaven vigents des de feia temps. L'any 1653 apareix un altre document que reafirma la prohibició: Edictes e crides fetes i publicades per manament del sereníssim senyor don Juan d'Àustria, fill del Rei. Tots els llibres o papers hauran de ser "vistos, reconocidos, corregidos y enmendados" abans d'imprimir-se. Es confiscaria l'imprès que no acatés l'ordre i l'autor romandria trenta dies a la presó. A l'impressor se li confiscarien tots els instruments tipogràfics i romandria seixanta dies a la presó.

2 En les llistes de classificació dels fulls propagandístics de la Col.lecció Bonsoms de la Biblioteca de Catalunya realitzades per Jaime Reula Biescas, no hi ha cap full del bàndol català escrit en llengua catalana durant l'any 1640. N'hi ha trenta-nou l'any 1641, vint-i-vuit l'any 1642, i la xifra minva considerablement els anys següents, només vuit l'any 1643. Segons Francesc Xavier Burgos i Manuel Peña Díaz "a partir de 1646-1647, la producción panfletaria prácticamente desaparecerá" (561). 
arriba i surt la informació, i altres qüestions tant econòmiques com socials fan que els fullets esdevingueren els textos impresos per excel.lència de la guerra. Amb els fullets, els impressors estalvien paper i tinta, i elaboren un document que vendran ràpidament, al contrari del llibre de producció complexa. Per bé que els fullets contenen informació sobre la guerra, incloven sobretot material propagandístic. La majoria de fullets-concretament la majoria de plecs poètics-segueix una estructura similar amb la repetició de temes i amb la mateixa simbologia. Catalunya esdevé una família i, també, en un locus amoenus; de fet, aquest espai privilegiat sofrirà canvis. Aquests canvis s'observen ràpidament amb la lectura del fullet: Catalunya passa de l'espai perfecte amb una naturalesa privilegiada a la desolació que comporta la destrucció brutal provocada per la guerra. Els castellans no només portaran penes a la família catalana, també destruiran aquesta naturalesa privilegiada: cremen boscos i tallen arbres. Els catalans, és a dir els segadors, s'encarreguen de lluitar per salvaguardar els cabalosos rius, les verdes valls, les fruites i les verdures dels horts catalans. Abans de tractar aquesta destrucció, cal situar els plecs poètics catalans de la guerra, veure les portades dels plecs on ja es dibuixen la família i la terra catalana $i$, també, cal descriure els protagonistes de la guerra: els catalans, els castellans i, breument, els francesos.

\section{La Guerra de Papers: de tractats polítics a plecs poètics}

La Guerra de Papers s'inicia després dels disturbis del Corpus Christi a la Barcelona de 1640 i amb la publicació de la Proclamación Católica a la Magestad Piadosa de Felipe el Grande (1640). ${ }^{3}$ Sortida de la impremta de Jaume Matevat i escrita en castellà pel monjo agustinià català Gaspar Sala i Berart (1605-1670), inaugura la primera batalla propagandística en forma de paper de la Guerra de Catalunya (Neumann 377). Encara que aquest memorial de greuges i les respostes provinents de la cort formen part d'aquesta explosió de papers, ${ }^{4}$ van influenciar poc en una població amb un índex d'analfabetisme alt i incapaç de seguir l'erudició històrica, teològica i jurídica d'aquestes obres.

3 Vegeu "Un alboroto católico: El factor religiós en la Revolució Catalana de 1640" i "La història en l'estratègia política dels dirigents catalans per enderrocar Olivares. Encara sobre la Proclamación católica" d'Antoni Simon i Tarrés.

4 Francisco de Rioja (1583-1659) s'encarrega de contestar la Proclamación Católica amb Aristarco o censura de la Proclamación católica de los catalanes (1640). Francisco de Quevedo (1580-1645) també va contribuir amb una resposta titulada La rebelión de Barcelona ni es por el güevo ni es por el fuero (1641). 
Jaume Romeu, Jaume Matevat i Gabriel Nogués també s'encarreguen d'imprimir els nombrosos pamflets catalans, en prosa i en vers, que es conserven de la Guerra de Catalunya. No es pot saber quin efecte van tenir aquests fullets, però la seva aparició adverteix que es distribuïen, es llegien o s'escoltaven, i que van transformar la Guerra dels Segadors en una guerra moderna, en la qual es batallava amb la ploma, amb el paper i amb la impremta. Els plecs poètics de l'època subratllen la reacció que provocaven aquestes notícies en la població catalana. En Còpia d'una carta (1642) no només s'apunta la influència de les gasetes sinó també com ensarronaven la població:

\author{
Que ab las gazetas \\ que ells aportavan, ${ }^{5}$ \\ i embahucavan \\ sols als badocs, \\ a tots los llocs \\ se $n^{\prime}$ enviassen. ${ }^{6}$
}

John H. Elliott reitera que la Guerra de Catalunya es compon de dues guerres: una de pobres contra rics, de la que no hi ha ni noms ni cognoms dels participants, i una altra de l'oligarquia catalana contra el centralisme castellà, capitanejada pel president Pau Claris i els seus homes (470). Les dues guerres $d^{\prime} E l l i o t t ~ s ' u n e i x e n$ en els plecs poètics catalans, on el conflicte entre pobres i rics, per una banda, i entre l'oligarquia catalana i la cort de Madrid, per una altra, desapareix, i, així, es converteix en una guerra entre catalans i castellans. L'objectiu dels plecs poètics-molts dels quals escrits per autors vinculats amb els representants de l'oligarquia catala$\mathrm{na}^{7}$-era convèncer la població que els enemics no eren ni els rics ni els

5 Per tal de modernitzà les grafies, he regularitzat l'ús de les majúscules, de la " $i$ " $i$ la " $y$ " (" $i$ "), he canviat la grafia "ñ" ("ny") i l'aglutinació de mots, he adoptat l'ús dels accents, de la dièresi, de l'apòstrof i del guionet del català actual.

6 Els plecs solts que es presenten aquí són només una petita mostra de la copiosa producció que generà la guerra. Tots ells estan al fons Bonsoms de la Biblioteca de Catalunya. Quan em refereixi a aquests poemes només escriuré les primeres paraules del títol. La informació completa es pot trobar a la bibliografia.

7 Per una banda, Jordi Rubió i Balaguer al.lega que alguns dels plecs catalans podien haver sigut escrits per membres del cercle literari de Vicent Garcia (1582-1623) o de Francesc Fontanella, sobretot aquells més elaborats (534). Per una altra banda, Anna M. Torrent afirma que "no hi ha dubte que els autors pertanyien a les capes més cultes de la societat" (82). 
francesos, sinó els castellans. Per convèncer la població s'havia d'utilitzar una simbologia apta per totes les classes socials i, especialment, per les classes populars. La guerra esdevé la destrucció de la terra catalana: un territori que anteriorment era fèrtil amb nombroses fruites i flors, o una mena de lloança a la vida rural catalana contra la destructora cort castellana. Els catalans es transformaran en segadors-soldats per salvaguardar aquesta terra privilegiada.

Els papers no van originar la guerra, i no hi ha suficients dades per saber com la maquinària propagandística posada en marxa per aquesta activa oligarquia catalana va condicionar i va canviar la trajectòria dels esdeveniments. No obstant això, els pamflets descriven la guerra desitjada per la burgesia catalana: una guerra molt diferent dels disturbis que s'estaven produint arrel la insatisfacció de les classes més baixes. Al costat d'això-i no elimino la possibilitat que es tracti d'una casualitat-, no es conserva cap fullet dels successos del Corpus Christi de 1640 a la ciutat de Barcelona; en canvi, n'hi ha diversos de la batalla de Montjuïc de 1641. Sense programa polític ni lideratge, el Corpus Christi es transforma en una revolta popular descontrolada. No hi va haver propaganda per uns disturbis desorganitzats, fortuïts, duts a terme per les classes més baixes i que van cloure amb morts imprevistes. Tot el contrari va succeir amb la batalla de Montjuïc: els dirigents catalans van encapçalar la batalla i van assegurar-se que gaudia d'una excel.lent propaganda escrita. No es pot saber si la impremta mobilitzà una població passiva, però, certament, l'oligarquia barcelonina aconseguí tot allò que el comte-duc d'Olivares (1587-1645) havia desitjat durant la guerra contra França: que els catalans participessin en la guerra.

La Guerra de Papers està formada per tres classes d'escrits: primer, apareixen uns tractats en castellà creats per un grup d'intel.lectuals catalans i castellans, i intercanviats entre Catalunya i la cort; segon, apareixen uns pamflets en prosa, que podien estar a l'abast del públic general, dirigits a persones lletrades i considerats intents periodístics; tercer-i són aquests els escrits que analitzaré en detall-, s'escriven els pamflets catalans en vers, dirigits al poble català $i$ en concret a un públic més general que potser no podia llegir o que no podia accedir als textos anteriors. Tot i que els pamflets en vers es podien llegir, també es cantaven i recitaven a les places i els carrers de Catalunya, i recorden les cançons medievals. Aquests plecs poètics es caracteritzen per ser curts i de llenguatge encomanadís per memoritzar i, a més, amb contingut propagandístic per enardir els ànims de les masses. 


\title{
LES PORTADES DE LA GUERRA
}

La finalitat dels plecs poètics no era únicament informar, sinó que consistia en tota una campanya propagandística amb el potencial de canviar el transcurs de la guerra, i amb el potencial de canviar la visió que els catalans tenien dels castellans. Si el comportament dels tercios en terres catalanes durant la guerra contra França perjudicà la imatge que es tenia dels castellans, aquests plecs poètics ajudarien a empitjorar la seva imatge. Aquesta campanya propagandística es fa en uns quatre fulls-l'extensió més corrent dels plecs poètics-dividits en tres o quatre columnes. Mentre alguns utilitzen cites llatines i cultismes-com ara Comparació de Cathalunya (1641)-la majoria canta victòria al ritme del "lum, fa, la, la, la, la" - com ara Relació del rendiment (1642). Tots ells estan carregats de castellanismes en una rima diversa. Els apariats són els més freqüents, seguits de les cobles i dels romanços. Tampoc hi manquen els quartets, els quintets, els sextets, els decasíl.labs, les dècimes, els sonets i els ovillejos. El format dels plecs poètics és senzill i utilitari. Quasi tots els plecs poètics segueixen el mateix format: portada inicial i text en els fulls posteriors.

La portada està formada pel títol, per la il.lustració, per la llicència, i pel nom i la ubicació de l'impressor i per l'any d'impressió. Freqüentment, el títol inclou mots com "còpia d'una resposta", "relació", "relació en rima", "cançó", "romanç", "tortes en vers" o "glossa". Alguns plecs poètics estaven escrits en prosa i ara han passat al vers:

\author{
he volgut fer \\ aquesta rima, $[\ldots]$ \\ i està ja escrit, \\ emperò en prosa. (Còpia d'una carta)
}

En general, el títol complet és un breu resum del poema: Còpia d'una carta; que envia Simon Vergés, a Bertran Gayris, en la qual li dóna relació de la derrota, i rendiment de l'exèrcit del Rei de Castella, del qual era General don Pere d'Aragó. En no pas poques ocasions s'inclou el tipus de composició utilitzada, un exemple és Romans a la victòria (1645). El tipus de composició pot estar inclòs dins del títol o en forma d'anotació sota del títol. El mot "vers" $s^{\prime}$ inclou sovint en el títol, com ara Algunas tortas en vers (1646). Les paraules "en rima de Jaume Roig" s'insereixen en el títol de Relació en rima (1642). L'autor adverteix que utilitza la rima de Jaume Roig (à-1478), o millor dit, que és la rima utilitzada en l'Spill (circa 1460).

Generalment, el títol integra dos binomis, per exemple, una compara- 
ció, o un destinatari i un remitent o dues contraposicions. En Relació en rima, la primera part o l'inici és la presa de Cotlliure i la segona part o el final és el rendiment de Salses-Cotlliure i Salses són els dos binomis. En Comparació de Cathalunya s'equiparen "els esdeveniments i personatges que intervingueren en la caiguda de Troia amb la situació que està patint Catalunya en aquells moments" (Ayats Pedregosa 139):

Te vull anar dient que Cathalunya, de ser un altra Troia, no s'allunya [...] I qui són exos grechs, que li fan guerra?

No et dic que castellans, la gent més perra.

En Còpia d'una carta, el remitent és l'autor Simon Vergés i el destinatari és Bertran Gayris; i en Cansó, al to de l'estudiant (1645), la tristesa del lleó es contraposa a la victòria de Flix.

A les relacions que estan signades per l'autor, el nom es pot incloure dintre del títol, com Còpia d'una carta que envia Simon Vergés, tanmateix, és més comú situar el nom sota del títol. Si s'inclou dintre del títol, no hi ha informació afegida sobre l'autor; en canvi si es troba sota del títol, es pot incloure la professió, com Relació del rendiment que està escrita "per Jofre Argeles" i després del cognom s'afegeix "notari". També es pot incloure el càrrec de l'escriptor $\mathrm{i}$ on es troba destinat, com A la famosa victòria, "Compost per Magí Ramon, soldat en Constantí". En Relació en rima, hi ha el nom de l'autor i la seva procedència però no s'inclou la professió: "Composta per Baldiri Malvesia natural de Picamoxons".

A la portada pot trobar-se el nom de l'autor, la professió, on està destinat i el lloc de procedència, però a part d'aquestes dades se sap poca cosa més. No és comú que el títol tingui la data exacta de composició, malgrat tot, en $A$ la famosa victòria, el títol acaba amb "a 10 de juny, any 1641". En aquest pamflet el nom de l'autor, el lloc i la data exacta també es localitza al final del poema, i el poeta adverteix que en el futur seguirà informant:
Assò és lo que ha succeït, darè del demés rahó, de Constantí a deu de juny lo soldat Magí Ramon.

Després del títol, el nom de l'autor i el tipus de composició es passa 
a la il.lustració, col.locada al centre de la portada. Les il.lustracions són senzilles i molt menys elaborades que les dels pamflets francesos. ${ }^{8}$ Joana Escobedo afirma que moltes d'aquestes il.lustracions es van realitzar durant el segle XVI i per aquesta raó són rudimentàries i no es conserven en bon estat (XVIII). Les il.lustracions tenen una relació al.lusiva o simbòlica amb el text que acompanyen i molt sovint l'impressor les utilitza repetidament en diversos pamflets.

Les il.lustracions varien en seva elaboració i, així mateix, no tots els pamflets tenen il.lustracions, per exemple, Algunas tortas no té cap mena de decoració ni de dibuix. De les il.lustracions menys elaborades destaquen els escuts, les insígnies militars, les torres, els cavallers-aquests darrers simbolitzen fortalesa i perseverança-la bandera catalana i la flor de lis-la primera subratlla el sentiment de pertànyer a un grup i la segona destaca I'aliança amb França. La bandera catalana i la flor de lis poden aparèixer separades o juntes en un mateix escut. És molt significatiu que la flor de lis aparegui constantment, fins i tot més que la bandera catalana. Era important convèncer la població que els francesos havien esdevingut aliats, i calia repetir que ja no eren els enemics. El poble havia de confiar en els francesos, i per això s'insereix la flor de lis a les portades, i el gall, al contrari, només es fa palès al text.

Les il.lustracions dels primers anys de la guerra són més elaborades que les il.lustracions posteriors. Hi ha gravats treballats amb cura, i cal aturar-se i analitzar-los. Dos d'aquests són Carta que ha enviada (1641) i Comparació de Cathalunya. El gravat més elaborat és Carta que ha enviada-vegeu la primera il.lustració. Dos grups de persones formen part del gravat: les dames estan situades a la dreta i els cavallers a l'esquerra. El títol i el text també estan dividits en dos grups. En el títol, "Perpinyà" representa el grup d'homes i "Catalunya" representa el grup de dones. El text es construeix en forma de carta dialogada entre "Perpinyà" i "Catalunya". Així, la vila de Perpinyà, personificada per un grup d'homes, envia una carta a Catalunya en la que narra les crueltats dels castellans. El representant del grup masculí es troba enfront de la representant femenina i manté un diàleg. El representant masculí és jove: Perpinyà encarna el fill de Catalunya. Els cavallers que el segueixen són vells perquè representen els homes savis de Perpinyà. Només s'observen les cares dels tres primers homes, els altres es confonen en la multitud. Tots aquests homes es reuneixen amb "Catalunya" per explicar-li els molts abusos als que estan sotmesos. L'"afligida vila, / que és

8 Cristina Fontcuberta i Famadas destaca les diferències entre els gravats francesos i els gravats catalans de la guerra. Els catalans són simples i de caràcter purament decoratiu. En canvi, els francesos són complexes i molt elaborats (154-155). 
Perpinyà", amb un moviment de mà, exposa a la dama els "torment(s)" i les "traicions" "d'estos sacrilegos soldats". Darrere els personatges s'observa l'estàtua d'un nen amb una llança i amb un escut, que simbolitza-com la torre i el cavaller-guerra, fortalesa i persistència.

Fig. 1

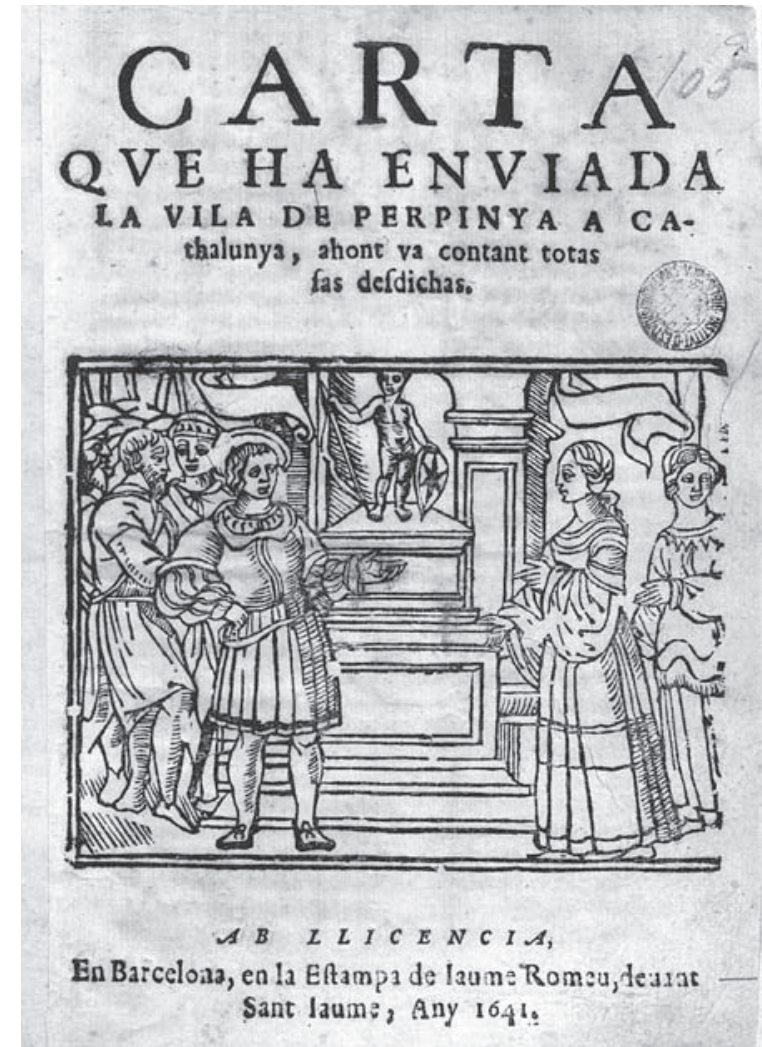

Carta que ha enviada la vila de Perpinyà a Cathalunya. F. Bon. 105.

Biblioteca de Catalunya, Barcelona.

Un dels plecs poètics de més valor literari que destaca per la mètrica regular, per la simbologia, per la ironia, per la barreja d'elements cultes i populars i per la portada amb elements de la naturalesa és Comparació de Cathalunya-vegeu la segona il.lustració. Així com el poema, la il.lustració de la portada està elaborada amb detall. La il.lustració es divideix en dues parts que pertanyen a dos bàndols oposats, és a dir a Catalunya i a Castella-, a diferència de Carta que ha enviada, on les dues parts pertanyien 
al mateix grup català. En Comparació de Cathalunya no hi ha ni mare ni fill, sinó que hi ha dos personatges masculins, i un és més jove i elegant que l'altre. El jove encarna Catalunya-una nova Catalunya desvinculada de Castella-i el vell encarna Castella. El jove està a la dreta, assegut sota un arbre, i el vell està a l'esquerra. La poca cura del vestit d'aquest darrer demostra el passat i la vilesa del vell. Castella o el vell té el cabell llarg, va despentinat i porta barba, a més, la seva cara és un lleó. A la banda dreta el jove està en perfecta harmonia amb tres ocells en un arbre i amb un gosset que dorm al costat del jove ben plantat. El jove descansa amb un ocell a la mà esquerra.

Fig. 2

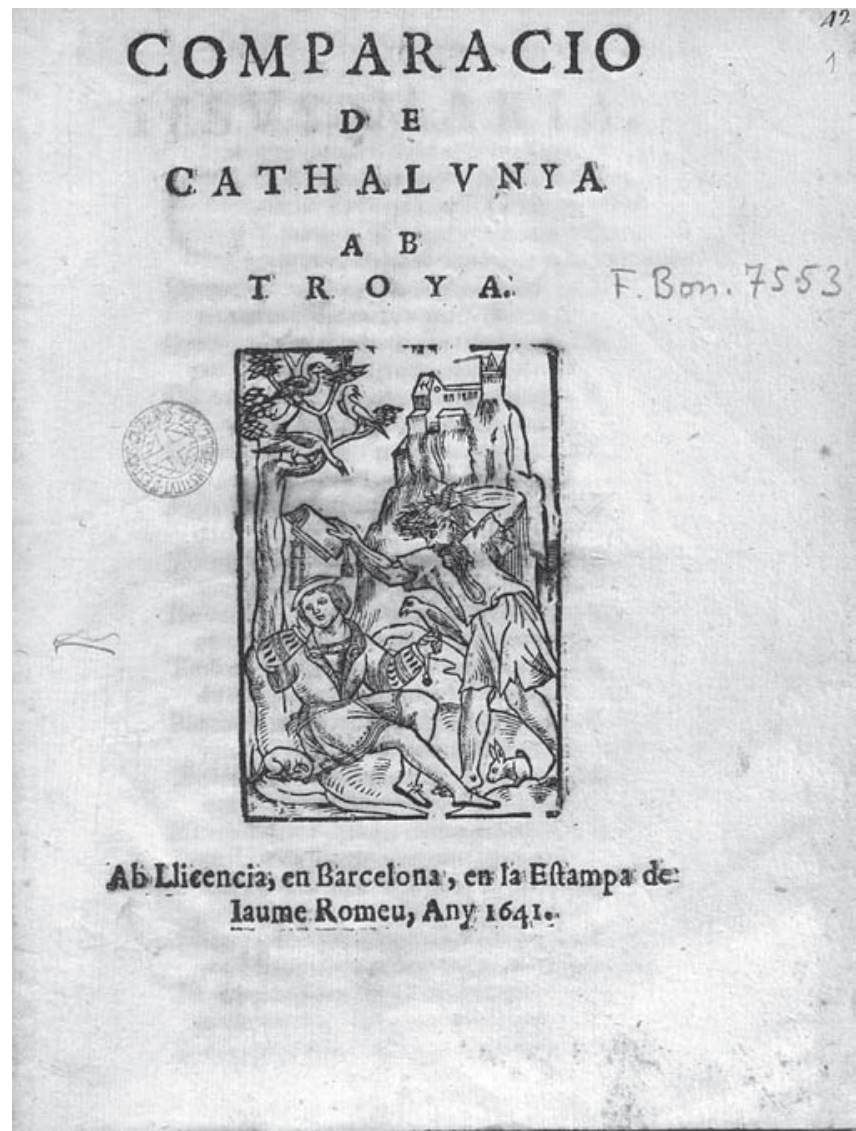

Comparació de Cathalunya ab Troia. F. Bon. 7553.

Biblioteca de Catalunya, Barcelona. 
L'harmonia del costat dret i la poca harmonia del costat esquerre del gravat recorden l'estructura mateixa dels plecs poètics. En un mateix poema es contrasta el passat de Catalunya, abans de l'entrada del marquès de los Vélez (1602-1647) i el present. La Catalunya del passat es descriu com una arcàdia on la població catalana viu en comunió amb la naturalesa, però amb l'arribada de l'exèrcit realista, l'arcàdia catalana es transforma en desolació:
Tallant, i cremant l'exèrcit
mira'l sobre Barcelona
de qui tresors, honras, vidas,
fan de mortal congoxa. (Algunas tortas)

La tranquil. litat del costat dret es trenca amb la intrusió del vell i destrueix la pau harmoniosa de Catalunya. Els ocells de l'arbre observen I'atac castellà, també, el conill surt del seu cau amb la intromissió del vell. Mentre el jove està en estat contemplatiu, el vell ataca el jove amb un llibre que té a la mà dreta. El vell no ataca ni amb armes de foc ni amb espases, sinó amb l'arma de la paraula escrita, és a dir, es dibuixa la Guerra de Papers que s'examina en aquest assaig. Lluny, s'observa el repetit castell.

Sota la il.lustració sempre es troben les paraules "Ab llicència", a excepció d'Algunas tortas que es localitza al final del poema. Després de la llicència s'escriu el nom de la ciutat on s'ha imprès, i que és Barcelona. ${ }^{9}$ Finalment, s'afegeix "en l'estampa" o "en casa" i el nom de l'impressor. Després del nom de l'impressor s'escriu el lloc on es localitzava la casa impressora. La impremta de Jaume Romeu estava situada enfront de la Parròquia de Sant Jaume al carrer Ferran; la impremta de Jaume Matevat es localitzava davant de la Rectoria del Pi i no lluny de la impremta de Jaume Romeu; la impremta de Gabriel Nogués tampoc es trobava lluny de les altres dues impremtes, al carrer Sant Domènec. La centralització d'aquestes impremtes - totes elles situades a l'actual Barri Gòtic-subratlla la relació amb els dirigents catalans, que segurament també vivien i es movien per la

9 Eulàlia Miralles identifica uns fullets impresos a Tarragona, a Girona i a Lleida: "Pel que fa a la resta del territori principatí, la publicació de propaganda impresa és migrada. A Tarragona, al taller dels Robert s'imprimeixen, que sapiguem, un parell d'opuscles tot just començada la guerra [...] Pel que fa a Girona, abans de 1652 només tinc notícia d'un fullet que tira Jeroni Palol [...] D'altra banda, a Lleida, Enric Castany publica notícies i pamflets que s'han de relacionar amb el conflicte" (191). 
mateixa zona. Cal senyalar que quan l'oligarquia barcelonesa s'exilia al Rosselló, les impremtes també van desaparèixer. La intelligentsia catalana i la impremta estaven situades al centre de Barcelona, que constituïa el centre operatiu de la resistència catalana contra Felip IV (1605-1665). La maquinària de la impremta s'estableix com el motor amb el qual arranca la Guerra de Catalunya.

Jaume Matevat és l'únic que de vegades canvia el format de la part inferior de la portada. En alguns plecs poètics inclou només el seu nom, en altres el seu nom i la ubicació de la impremta. Amb l'any d'impressió clou la portada. En el primer full, després de la portada, repetidament es traça una sanefa horitzontal. Sota la sanefa i en majúscules es troben les paraules "Jesús, Maria, Joseph" o només "Jesús, Maria", i es passa al text rimat.

\section{UnA GUERRA EN VERS}

El nom de l'autor no és tan freqüent com el seu protagonisme durant el poema. Alguns autors que s'identifiquen són Jofre Argeles, Baldiri Malvesia i Magí Ramon. L'autor-que escriu en primera persona-justifica la seva obra i es disculpa pels errors comesos, sobretot els errors en la versificació. Després de demanar disculpes, proclama la seva honestedat, promet una continuació i dóna consells. També pot afegir el fet que Catalunya està passant un mal moment:

A sa mare Cathalunya

desitja salut, i gràcia.

Molta salut vos desitjo,

però no us la puch donar,

que la poca de que gozo,

a penas la puch conservar. (Carta que ha enviada)

El poema va dirigit a un lector o a un públic amic: "o tu Lector" (Còpia d'una carta), "lo meu amich" (Còpia d'una carta), i amb regularitat el poeta presenta la tristesa que l'envolta: "Com vols, que conta casos llastimosos, / que no vinga a tenir los ulls plorosos?" (Comparació de Cathalunya). Donar gràcies a Jesús i a Maria i demanar ajuda als sants, també és un començament regular:

Dem gràcias al Senyor,

i a la sagrada Mare,

preguem contra el Lleó 
que Eulària ans empare,

ay com sempre ens ha guardat

lo nostre Principat. (Cansó, al to de l'estudiant)

L'autor integra pauses i fa parèntesis durant la composició: "(com vaig dient)" i "(com tinch dit)" (Còpia d'una carta). Amb aquestes paraules introdueix l'element oral i amb "(molt importava / notar axò)" (Còpia d'una carta) subratlla les parts essencials del poema. També interromp per donar I'opinió: "(que brava cosa!)" (Còpia d'una carta). Finalment, l'autor s'obliga a acabar, ja que ha exposat amb detall la situació que es troba Catalunya i no pot allargar-se més per la manca de paper:

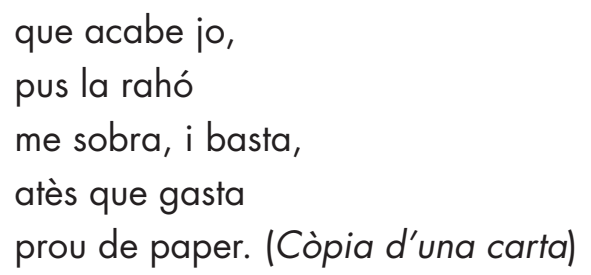

Els plecs poètics tenen, sovint, una mateixa estructura. Com a exemple seguiré Carta que ha enviada, que comença amb una introducció:

La trista, i afligida vila, que és Perpinyà nomenada, a sa mare Cathalunya desitja salut, i gràcia.

De la introducció passa a l'aflicció dels catalans i a les crueltats comeses pels castellans. El turment castellà ha estat comès a través dels seus actes $\mathrm{i}$ també a través de les paraules. En els següents versos, el terme "paraulas" es refereix a la Guerra de Papers:

D'estos sacrilegos soldats, que ab obras, i paraulas usan ab mi crueltats.

De tot bé estich privada, cosa no us puch enviar, si no és llàgrimas vivas. 
L'autor no entén les accions dels castellans i justifica les accions dels catalans. A partir d'aquest moment, apareixen els francesos, els quals arriben per rescatar els catalans. L'ajut francès es presenta justament abans del diví: "que lo cel és ajudador" (Ramon). A continuació s'inclou una llista llarga de sants. Els més repetits són Sant Magí, Santa Eulàlia, Santa Tecla, Santa Cecília i, sobretot, Sant Jordi. Els sants sempre es troben al costat dels catalans i els protegeixen de les crueltats castellanes. Déu i la Verge també estan junt els catalans, i la revolta és part d'un pla diví per ajudar els catalans. El fullet acaba amb un acomiadament $\mathrm{i}$ amb el reiterat tema de la manca de paper: "Que no em puch més allargar, / que tantas llàgrimas llanzo, / que em fan lo paper gastar". La manca de paper suggereix la crisi del Ilibre del segle XVII. Els plecs poètics suplanten els llibres per la manca de paper, i malgrat els pocs fulls utilitzats en els plecs poètics, els autors són molt conscients de l'estalvi del paper. Els plecs poètics acaben amb tres finals comuns: "Finis", "Fi" i "Laus Deo", tot i que es poden oblidar aquestes paraules, com succeeix a Clarí de veritats (1641).

Clarí de veritats segueix la mateixa estructura que Carta que ha enviada i, a més, resumeix els moments històrics claus de l'inici de la guerra. Els esdeveniments històrics es relaten a partir d'un recorregut per la geografia catalana. Comença amb l'entrada del marquès de los Vélez a Tarragona: "[...] a Tarragona / perquè celebrà l'entrada, [...] / Lo gran marquès de los Vélez". Seguidament, l'autor fa un resum ràpid de l'avançament castellà per terres del sud de Catalunya, fins a l'arribada a Barcelona. Els castellans entren a Barcelona i s'inicia la batalla de Montjuïc. Aquesta batalla és un dels esdeveniments més repetits en els plecs poètics catalans:

De Montiüch cavaller, que galantea per dama a la noble Barcelona digna de ser festejada.

\section{ELS PROTAGONISTES de LA GUERRA DE PAPERS}

Si per una part la batalla de Montjuïc està present en els plecs poètics $i$ en les obres catalanes de l'època, com el Panegíric a la mort de Pau Claris (1641) de Francesc Fontanella (1622-1682/1683), ${ }^{10}$ per una altra part,

10 Per una biografia detallada de Fontanella, vegeu la introducció d'O he de morir o he d'amar de Pep Valsalobre, d'Eulàlia Miralles i d'Albert Rossich. 
els disturbis del 7 de juny de 1640 a Barcelona desapareixen dels escrits catalans-com afirmava anteriorment. Si bé s'anomena el virrei Santa Coloma: "que quan governà Coloma" (Clarí de veritats), la seva mort i els actes violents del Corpus de Sang no apareixen en cap plec poètic. Santa Coloma, igual que tots els protagonistes de la guerra que pertanyen al bàndol castellà, és ridiculitzat i descrit amb ironia popular: "De Troia diu, que la perdé una Poma, / de Cathalunya una Coloma" (Comparació de Cathalunya). Els catalans dels fullets són víctimes de les crueltats dels catellans, i és clar, són valents i gloriosos:
Però no m'espanto jo,
que faltant en sa campanya
lo valor de Cathalunya
se'ls enturbia la fama. (Clarí de veritats)

Els autors dels plecs poètics poden incloure una llista dels catalans valerosos. A la famosa victòria, la llista és de cinquanta-set noms.

Els francesos apareixen en diverses ocasions, però a part de mencionar el seu ajut, no es fa cap descripció d'ells: són senzillament els aliats dels catalans sense incloure cap tret que els caracteritzi. Com han passat d'enemics a aliats, fer una lloança emotiva dels francesos podria semblar exagerat o poc creïble, per tant, s'opta per una simple imatge positiva. Ningú pot dubtar de tal aliança, per això la unió Catalunya-França és un acte diví: "França la més enemiga / air, vui la defensora? / [...] Déu la causa sola" (Algunas tortas). Déu ha disposat la guerra amb Castella i I'aliança amb França.

Els castellans són totalment oposats als catalans i es descriven com cruels, covards, fanfarrons, mentiders, "sacrilegos e inhumans" (Resposta que fa Cathalunya): "Un dels estereotips més aplicats al castellà dels segles XVI i XVII és la seva bravuconería, el seu caràcter arrogant i fanfarró" (de Lucas 588). Sovint els autors relacionen els castellans amb llops disfressats d'ovelles, escorpins cruels i gossos rabiosos. No hi ha llistes llargues dels militars castellans perquè hom els observa com un grup; tampoc hi ha llistes del grup francès. Quatre són els protagonistes francesos dels plecs poètics: monsieur de la Mothe, el comte d'Harcourt, el comte de Plessis i Lluís XIII. Els militars castellans apareixen encara menys que els francesos. Només dos noms es repeteixen als plecs poètics: el marquès de los Vélez i el comandant de les galeres, García de Toledo. Els tres castellans protagonistes dels plecs poètics, i grans enemics dels catalans, són el protonotari 
Villanueva (1594-1653), el rei Felip IV i "qui s'enduu la palma és sens dubte el comte-duc d'Olivares, el valido o el 'neró' (com també se li diu)" (Torres Sans 155). A gairebé tots els poemes apareix un d'ells. La burla a Olivares, a Villanueva i a Felip IV és constant. Si bé els dos primers són atacats per ser considerats els responsables dels mals de Catalunya, no s'entén la postura de Felip IV. Durant els primers anys de la guerra, el rei sembla víctima dels seus ministres i no és conscient del que succeeix. Malgrat la guerra, els catalans es consideren súbdits del rei. Felip IV deixa de ser rei dels catalans en el decurs de la guerra. Ara el rei ja no és enganyat, sinó que la seva política és tan cruel com la d'Olivares i la de Villanueva. Cal comparar la visió del rei d'un plec poètic de 1641 amb un altre de 1643. Al primer, els catalans se senten afligits per l'actuació del rei: "Ja no m'estima lo Rei" (Carta que ha enviada). Al segon ja s'adverteix la tirania de Felip IV: "Aqueix dur Rei castigant" (Als mals efectes), i deixa de ser rei de Cathalunya: "Ells són causa que Felip, / no és ja Rei de tota Espanya" (Clarí de veritats). El rei apareix molt més en els fullets dels primers anys que en els dels anys posteriors. L'oblit de Felip IV va lligat al nou protagonisme de Lluís XIII, però per poc temps: el rei francès morirà l'any 1643.

En no pas poques ocasions el rei apareix manipulat pel comte-duc d'Olivares, postrat al llit, malalt o adormit sense saber tot allò que passa als seus dominis. En Sátira, ${ }^{11}$ el malalt Felip IV està cuidat pels seus dos infermers: Olivares i Villanueva. ${ }^{12}$
[...] està malalt
lo gran monarca Phelip.
Diuhen que de mal govern
poch a poch se va morint.
No adverteix res quan li parlan, perquè sempre està dormint $[\ldots]$
No respon quan lo preguntan $[\ldots]$
dos enfermers que el governan
sens deixar-lo dia i nit. (Còpia d'una carta)

11 Aquesta sàtira es troba a Claris y son temps.

12 Les mateixes imatges del rei, del comte-duc i del protonotari es troben a les cançons populars castellanes. A Saragossa apareix una dècima - reproduïda a Claris y son temps- tan descarada com les dels plecs poètics catalans. A la part superior i abans de començar el poema hi ha pintat un taüt, una corona reial, un espectre i un capel de cardenal. El dibuix s'explica amb 
En Glosa catalana - cançó que es diferencia dels altres plecs poètics per conservar-se només en forma manuscrita-la sàtira és inclús més enginyosa: "Diu-se que lo Comte Duc. . . . Un ruc / la Real Magestat. . . . Un fat / i lo seu Protonotari. . . . Sectari".

\section{La Catalunya dels plecs poètics}

Tot i que hi ha castellans, francesos i catalans en els plecs poètics, tota I'acció té lloc a Catalunya. No es descriu ni la cort ni la resta de la península ibèrica, només es descriu la geografia catalana. En els plecs poètics, hi ha dues barreres que separen Catalunya. La primera barrera és temporal: hi ha la Catalunya d'abans de la guerra i la Catalunya de la guerra. La Catalunya d'abans de la guerra es presenta com una arcàdia en la qual els catalans viven en perfecta harmonia:

Què són mare d'aquells temps

tant felices, i dorats,

de que alegra gozava,

com axí se'n són anats?

Què és d'aquella hermosura,

que tenia en temps passat?

Que era un jardí de regalos. (Carta que ha enviada)

Igual que el costat esquerre de la il.lustració de Comparació de Cathalunya, la Catalunya d'abans de la guerra és descrita com un locus amoenus de terres fèrtils i de camps amb flors. Amb l'entrada de l'exèrcit castellà, la situació canvia, i a Catalunya regna el desordre total: "Ni rosas, jardins, ni violas, / ni cosa bona hi ha ja" (Carta que ha enviada). Pau i flors són reemplaçades per soroll i per armament: "Mosquets, i arcabussos, / balas, metxa, alquitrà, / pólvora" (Argeles). Amb el desordre apareix la malaltia. Catalunya ha perdut la salut i Castella és qui li arrenca la vida. ${ }^{13}$ Es tracta del mateix atac que va tenir lloc a Troia, equiparació que s'observa a Comparació de Cathalunya i en diversos plecs poètics. A més de l'associació

els versos: "Aquí yace un rey, no entero, / herido de un cardenal; / de un monte Rey un Toral, / de un Leganés lance fiero. / Salazar le hirió primero, / Olivares le perdió, / Villanueva le hechizó, / Catalanes le mataron, / monjas le amortajaron / y Portugal le enterró" (165).

13 Sobre el tema de la malaltia a Comparació de Cathalunya ab Troia, vegeu "Infección y resistencia: Discurso biológico en la Comparació de Cathalunya ab Troya" de Cynthia J. Malik. 
Troia-Catalunya, també s'associen els catalans amb els jueus. Catalunya es troba en la mateixa situació d'esclavitud que el poble jueu: "tota Cathalunya esclava" (Als mals efectes). Els catalans, com els jueus, tenen a Déu de part seva: "los Lleons al Castellà / los Jueus al Messias" (Als mals efectes). Aquest mateix paral-lelisme és tractat extensament per Francesc Fontanella en el Panegíric a la mort de Pau Claris (1641). Per Fontanella, Pau Claris representa Moisès que allibera el poble català de l'opressió castellana. En aquesta simbologia jueva, Pau Claris representa Moisès, la muntanya de Montjuïc es relaciona amb el Sinaí i Barcelona amb Jerusalem. ${ }^{14}$ També per Gaspar Sala i Berart, Pau Claris és el "Moisés del pueblo catalán" (3) en Lágrimas catalanas (1641).

Si la primera barrera era temporal, la següent és geogràfica. Catalunya és un territori ben delimitat, compost per muntanyes, valls, camps, ports $\mathrm{i}$ el mar:

lo mappa, la terra tota ninguna veuràs més bella, que Cathalunya se mostra.

Neptuno de llarch la banya, Apolo de ple la dora [...] ab ports [...] Empina montanyas altas, i amenas valls. (Algunas tortas)

La geografia catalana s'observa a través d'un mapa físic amb els noms de les muntanyes i dels rius. D'aquesta manera, Catalunya es relaciona novament amb la representació gràfica. Si les armes propagandístiques s'han convertit en pamflets, el territori català s'ha convertit en un mapa. La Barcelona burgesa i urbana de la guerra es val de la impremta i de la cartografia per un atac modern.

Al mapa físic s'afegeix el mapa polític. Els plecs poètics dibuixen el recorregut de la guerra, que passa per les ciutats en les quals tenen lloc

14 Encara que etimològicament Montjü̈c pot provenir de la forma llatina Mons lovis, és a dir muntanya de Júpiter -en el Montjuïc d'Amor, firmesa i porfia (1642) de Fontanella s'ubica l'oracle de Júpiter-, tradicionalment es relaciona amb muntanya dels jueus, per l'existència d'un cementiri jueu en aquesta muntanya durant l'època medieval. 
les batalles més importants. El recorregut sempre és de sud a nord. Segons I'any d'impressió, hi ha unes ciutats o unes altres. Si més no, hi ha algunes ciutats que sempre apareixen, com Tortosa i Barcelona:

Ja enganyaren a Tortosa,

i lo camp contaminaren,

i ab promeses entraren al punt dins de Tarragona.

Baxaren per lo Panedès [...]

ribaren a Martorell [...]

A Montjuïch com a mastins

pujaren ben informats. (Resposta que fa Cathalunya)

Els plecs poètics segueixen el mateix recorregut de l'exèrcit castellà: entren, baixen, busquen, arriben i pugen per les terres catalanes. En tota ciutat i poble on els castellans s'aturen, generen devastació. Doncs bé: quan els castellans arriben a la ciutat de Barcelona i concretament a la muntanya de Montjuïc la situació canvia, i es retiren. Barcelona és el centre neuràlgic, on es creen els plecs poètics $i$ des d'on aquests surten per ser llegits i cantants. Com la Jerusalem dels mapes medievals, Barcelona s'ha convertit en el centre d'aquest mapa català.

\section{Conclusió}

Els elements de la naturalesa, "flors, en fruits, i verdura" (Algunas tortas), es repeteixen constantment en els plecs poètics, i sobretot els noms d'animals. Lleons, llops, tigres, braus, cavalls, ases, mules, ovelles, gossos, mastins, genetes, galls, gallines, serps, salamandres, bacallans, escorpins, escarabats $\mathrm{i}$ aranyes apareixen repetidament. Els plecs poètics transformen la Guerra de Catalunya amb una guerra camperola, o més ben dit en la Guerra dels Segadors. La burgesia catalana havia de modificar el format i el llenguatge per poder guanyar la guerra: els tractats filosòfics, polítics i religiosos s'abandonen, i les noves armes de la guerra seran senzills plecs poètics. L'erudició queda reemplaçada per la cançó. En fi: és l'oligarquia catalana qui s'amaga darrere la maquinària propagandística. Són ells el "soldat en Constanti" i el "notari", que des de la urbana Barcelona dels tallers d'impressió es desplacen al camp per lluitar junts contra l'enemic castellà. Els catalans es transformen en amics, en germans i en fills, però sobretot en segadors. La família-i concretament una família rural -és el recurs propagandístic per excel.lència dels plecs poètics. Mares, fills i filles, 
germans i germanes i parents del camp català són els protagonistes sense nom dels plecs poètics: "Allí se troban junts / parents, fills, i germans" (Argeles). L'oligarquia catalana s'unirà al poble per formar, així, aquesta família dels plecs poètics i que es diu Catalunya.

\section{Bibliografia}

(1646): Algunas tortas en vers a las voluntats exposadas a las moltas que vui se donan en prosa. Barcelona. Matevat.

(1643): Als mals efectes de tota Cathalunya. Barcelona. Matevat.

ARGELES, J. (1642): Relació del rendiment de la plassa de Perpinyà ab las festas que es feren alrededor. Barcelona. Gabriel Nogués.

AYATS PEDREGOSA, L. (1994): "Comparació de Cathalunya ab Troia", en Estudi general. 14. Pp. 137-157.

BURGOS, F. X., i M. PEÑA DÍAZ. (1984): "Aportaciones sobre el enfrentamiento ideológico entre Castilla y Cataluña en el s. XVII. (La publicística catalana)", en Actes Primer Congrés d'Història Moderna de Catalunya. 14. Barcelona. Pp. 557-567.

(1645): Cansó, al to de l'estudiant, i de la tristesa del lleó, i victòria de Flix. Barcelona. Matevat.

(1641): Carta que ha enviada la vila de Perpinyà a Cahtalunya, a on va contant totes ses desgràcies. Barcelona. Jaume Romeu.

(1641): Clarí de veritats, valentia cathalana, derrota de castellans alumbrats, retiro, i galliner de Madrit. Gall, i flor de lliri de Franca. Barcelona. Gabriel Nogués.

(1641): Comparació de Cathalunya ab Troia. Barcelona. Jaume Romeu. COROLEU, J. (1880): Claris y son temps. Quadros de costums políticas del sicle XVII. Barcelona. La Renaixensa.

(1653): Edictes e crides fetes i publicades per manament del sereníssim senyor don Juan d'Àustria, fill del Rei, lloctinent i capità general en lo present Principat de Cathalunya i Comtats de Rosselló i Cerdanya. Barcelona. Joseph Forcada.

ELLIOTT, J. H. (1996): La revolta catalana 1598-1640: Un estudi sobre la decadència d'Espanya. Barcelona. Vicens-Vives.

ESCOBEDO, J. (ed.). (1988): Plecs poètics catalans del segle XVII de la biblioteca de Catalunya. Barcelona. Biblioteca de Catalunya.

ETTINGHAUSEN, H. (1993): La Guerra dels Segadors a través de la premsa de l'època. 4 vols. Barcelona. Curial.

FONTANELLA, F. (2008): Panegíric a la mort de Pau Claris. Montserrat Clara- 
só i Maria-Mercè Miró (ed.). Barcelona. Fundació Pere Coromines.

FONTANELLA, F., i J. RAMIS I RAMIS. (1982): Teatre barroc i neoclàssic. Maria-Mercè Miró i Jordi Carbonell (ed.). Barcelona. Edicions 62.

FONTCUBERTA I FAMADAS, C. (2003): "Art i conflicte: L'ús de la imatge a la Guerra dels Segadors", en Pedralbes: Revista d'Història Moderna. 23. Pp. 147-164.

Glosa cathalana.

LUCAS, N. de. (2008): "Catalans i castellans: estereotips durant la primera meitat del segle XVII", en Pedralbes. 28. Pp. 585-600.

MALIK, C. J. (2009): "Infección y resistencia: Discurso biológico en la Comparació de Cathalunya ab Troya", en Res publica. 21. Pp. 107-125.

MALVESIA, B. (1642): Relació en rima de Jaume Roig, de tot lo que ha succeït dintre, i fora de Perpinyà en son siti, fins al rendirse. I des de la presa de Coblliure, fins al rendiment de Salsas, axí per terra com per mar. Barcelona. Jaume Romeu.

MIRALLES, E. (2012): "Els escriptors catalans en una Europa en conflicte: La propaganda política impresa de la Guerra dels Segadors", en Caplletra. 52. Pp. 181-205.

NEUMANN, K. (1998): "La justificación 'ante el mundo'. Difusión y recepción de la propaganda catalana en Europa en 1640", en Pedralbes: Revista d'Història Moderna. 18.2. Pp. 373-381.

QUEVEDO Y VILLEGAS, F. de. (1961): Obras completas: Obras en prosa. Felicidad Buendía (ed.). Madrid. Aguilar.

RAMON, M. (1641): A la famosa victòria que han alcansada dels enemics, los tercios d'infanteria, i cavalleria cathalana, i francesa, en lo siti de Tarragona. Barcelona. Jaume Romeu.

(1641): Resposta que fa Cathalunya a vna carta que li ha enviada la vila de Perpinyà, ab la qual plora sas desdichas pateix en recompensa d'innumerables servicis. Barcelona. Jaume Matevat.

REULA BIESCAS, J. (1991): "1640-1647: Una aproximació a la publicística de la Guerra dels Segadors", en Pedralbes: Revista d'Història Moderna. 11. Pp. 91-108.

-. (1996): "Guerra y propaganda en la Cataluña de 1635-1659", en Historia y comunicación social. 1. Pp. 87-108.

RIOJA, F. de. (1640): Aristarco o censura de la Proclamación católica de los catalanes. Madrid.

ROIG, J. (1928): Llibre de les dones, o Spill. Francesc Almela i Vives (ed.). Barcelona. Els Nostres Clàssics. 
(1645): Romans a la victòria que las armas invictas de França han tingut contra del Rei de Castella en Rosas. Barcelona. Matevat.

RUBIÓ I BALAGUER, J. (1953): "Literatura catalana", en Historia general de las literaturas hispánicas. Guillermo Díaz-Plaja (ed.). Barcelona. Barna. SALA, G. (1641): Lágrimas Catalanas. Barcelona. Gabriel Nogués. -. (1640): Proclamación Católica a la Magestad Piadosa de Felipe el Grande. Barcelona. Jaume Matevat.

SIMON I TARRÉS, A. (2003): "Un alboroto católico: El factor religiós en la Revolució Catalana de 1640", en Pedralbes: Revista d'Història Moderna. 23. Pp. 123-146.

-. (2007): "La historia en l'estratègia política dels dirigents catalans per enderrocar Olivares. Encara sobre la Proclamación católica", en Pedralbes: Revista d'Història Moderna. 27. Pp. 97-112.

TORRENT, A. M. (1984): "Poesia barroca de la Guerra dels Segadors", en Els Marges. 31 . Pp. 81-100.

TORRES SANS, X. (2007): La Guerra dels Segadors. Barcelona. Eumo. VALSALOBRE, P., E. MIRALLES, i A. ROSSICH (ed.). (2015): "Introducció", en $O$ he de morir o he d'amar. Barcelona. Empúries. Pp. 9-45.

VERGÉS, S. (1642): Còpia d'una carta; que envia Simon Vergés, a Bertran Gayris, en la qual li dóna relació de la derrota, i rendiment de l'exèrcit del Rei de Castella, del qual era General don Pere d'Aragó. Barcelona. Jaume Romeu. 